\title{
Die Design for Near-Net Shape Forging
}

\author{
J. Čermák, G. Gráf
}

This paper discusses the use of conventional forging equipment for the manufacture of precise forging without flash. An analysis is presented of the factors influencing the forging process and the conditions for establishing this technique in a forge based on practical experience at the SKODA Auto forge. The main problem is usually the excess volume of billet material. Three basic forms of die design for overload protection are illustrated and discussed.

Keywords: flashless forging, die design, accommodation space, spring-operated device.

\section{INTRODUCTION}

The production contract between a customer and a forging company starts with the initial customer inquiry and is concluded by the customer's final approval. The customer's technical specification contains requirements with which both the forger and final forging must conform. The specification usually covers:

- Forging material - chemical composition, heat treatment.

- Drawings and dimensions - forging drawing and final machine drawing.

- Macroscopic grain flow and grain size requirement.

- Post production tests (destructive and/or non-destructive) and quality management.

- Number of items to be produced, terms of supply.

As the contract will be agreed upon partly on the basis of the forging drawing, this drawing is of great importance. The forging drawing must state the tolerance range within which the forging should be produced. A forging design is based on part shape complexity, material composition, required precision, production run, and type of forging machine used.

The drawing of a forged part that has been accepted by the customer is the only valid document for inspection of the forged part. The forging design procedure is therefore one of the most important stages in forging production. The designer starts from the final machine drawing including details and dimensions of the machining locations, relevant information on machining operations and the function of the component. After the type of production unit has been selected, forging allowances and machining allowances are added to the component profile. Finally, the forging tolerances are added versus the material and forging complexity factor. An important result is that the forging design may substantially influence the production run and the auxiliary steps, tool design and its lifetime complexity, as well as material costs due to allowances.

\section{Near-Net shape forging}

The term near-net shape forging indicates that some but not all of the forging surfaces require only minimal machining or finishing. This term is used in connection with the term precision forging. Precision forging is also described as close-tolerance forging in order to emphasise the goal of achieving, solely through the forging operation, the dimensional and surface finish tolerances required in the finished part. The precision of a forging is defined in terms of its conformity to the finished-part requirements as regards overall geometry, dimensional tolerance, and surface finish. The motivation for precision forging is as follows:

- Reduction of material costs, which are about the half of the total cost of forging. A significant amount of input material ( 5 up to $30 \%$ ) is associated with the forging flash. The design of precision forging usually minimizes and sometimes completely eliminates flash.

- Reduction of costs associated with the machining allowance. These costs include not only the labour and indirect costs of the machining and finishing operations but also the cost of the excess raw material that is lost during machining.

- The mechanical properties of precision forging are often superior to those of forging that has undergone extensive machining. This occurs because the forged microstructure is preserved intact in precision forging.

As already mentioned, the main reason for installing of the methods of near-net shape forging is to reduce production costs, since the total forging costs usually consists mainly of material costs. This requirement can be achieved by changing the forging shape and/or by reducing the machining allowances [1]. An example of these shape changes is given in Fig. 1 .
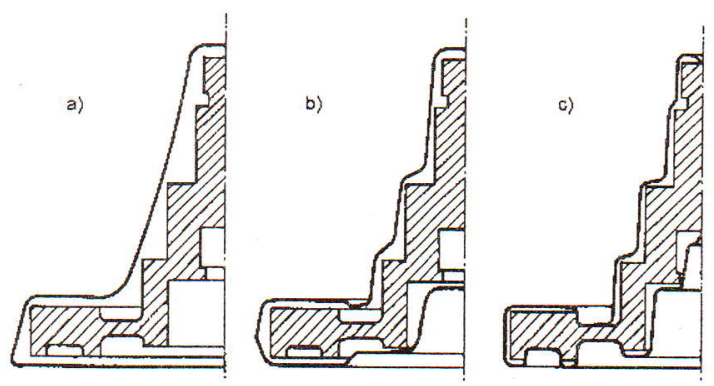

Fig. 1: Possible changes of forging shape. Adapted from "Schmiedeteile" [1].

The forging shape is related to the die design. A more complicated shape usually means a more complicated tool, and therefore a much higher tooling cost. This approach is justified with increasing size of the production run, if we con- 
Table 1: Composition of finished part costs

\begin{tabular}{|l|c|c|c|c|c|}
\hline Production run & Total cost & Machining cost & Forging production cost & Material cost & Tooling cost \\
\hline Low (Fig. la) & $100 \%$ & $52 \%$ & $12 \%$ & $22 \%$ & $14 \%$ \\
\hline Medium (Fig. Ib) & $86 \%$ & $38 \%$ & $20 \%$ & $20 \%$ & $22 \%$ \\
\hline High (Fig. 1c) & $72 \%$ & $19 \%$ & $30 \%$ & $19 \%$ & $32 \%$ \\
\hline
\end{tabular}

sider the total costs for finished part production. The total costs are the sum of the forging costs and the machining cost. The total production costs decrease even if the costs of the forged part increase, as the structure of the costs changes. Roughly estimated, the percentage share for a given part is given in Table 1.

\section{Basic factors influencing near-net shape forging}

\subsection{Forged material}

The behaviour of the forged material is characterised by its chemical composition, mechanical, chemical and processing properties. The forging temperature and the appropriate range influence the formability, the surface quality, the dimension tolerances, and the wear of the dies. Decreased formability means that the metal flow is restricted, and higher pressure is necessary. The wear of the die increases and the die life decreases.

\subsection{Forging shape difficulty}

The shape of a forging has a strong influence on the final cost of tooling. Increasing forging shape difficulty means that the flow of the material is more complicated. It is therefore is necessary to use more preform operations, so the die life of the tool decreases, the tooling design becomes more complicated, and supplementary operations, such as punching, sizing etc., are often needed.

\subsection{Billet volume variation}

If the input material is in the form of a bar, the accuracy to which billets may be prepared depends on the variation of the cross-section and the variation in cut-off length. Variation in cross-section depends on the type of bar and its quality (black bar, bright bar, peel bar). Two methods are available for separating: sawing and shearing. Shearing is preferred, as no material is wasted. Volume variations in billets cut from bars decrease with increasing height-to-diameter ratio. The greatest accuracy of volume in the case of black bars is obtained when the ratio of the height to the diameter of the billet is equal to the ratio of the variation in height to the variation in diameter [2]. In the case of bright bars, volume accuracy is dependent on bar diameter.

\subsection{Flash}

Flash consists of flash land and gutter. It serves to accommodate the excess material and to create the necessary pressure in the die cavity. Excess material is usually needed to compensate for variations in billet volume and die cavity growth due to wear. On the other hand, flash land involves increasing the forging load. The load necessary to forge a shape can be reduced dramatically by eliminating this flash land. At the same time the material flow should be carefully checked, because this change can cause the formation of flow defects and/or under-filling of the die cavity. To eliminate normal flash it is necessary to change the die design. The reason is that excess billet volume may cause overloading of machines, over-stressing of dies, and the forged height will depend on the billet volume.

\subsection{Machining allowances}

Machining allowances refer to the amount of material that is to be machined from the forging to obtain the finished part. Allowances always mean extra material, and they increase the costs. Machining allowances are dependent on the material forged (degree of formability), on the type of production unit being used, on the maximum dimensions of the part, and on customer requirements. Therefore an agreement must be made between the forger and the customer. Machining allowance values are not given in the current EU standards. The recommended European values are between minimum $1 \mathrm{~mm}$ and maximum $5 \mathrm{~mm}$, per surface [3]. In SKODA Auto forge shop practice, the amount of machining allowances is chosen according to the following considerations:

- Type of input bar (peeled bar - rolled bar).

- Tool design (accommodation of excess billet material, position of parting plane).

- Technical state of the forging machine (tolerances, mismatch, temperature stability, $c_{\mathrm{m}}, c_{\mathrm{p}}$ ).

- Billet shape, volume and precision of dimensions (method of bar separation).

\subsection{Draft angle}

The forging must be able to be removed from the tooling after the forging process is completed. A slight draft should be added to parallel surfaces to facilitate ejection. The value of the draft angle depends on the die design and the method of removal from the die cavity (ejection by pins or manual removal). Elimination of draft is limited by the capacity of the ejection mechanism of the forging equipment, by the strength of the workpiece material at the ejection temperature, and by the wear of the tooling and/or damage to the surface of the workpiece. A specific role is also played by the version of the given forging machine and by the actual state of ejecting mechanism. The basic rule is :

- A greater value of the draft angle means more excess material. This material should either be removed (more machining) or, if it is left, there will be heavier forging.

- A lower value means that the number of tool refurbishments is smaller. The share of the tooling cost in the forging price will be higher. In forge shop practice it is necessary to look for a compromise solution. 


\subsection{Fillets and corners}

Corners and fillets are curved connecting surfaces that smoothly unite the intersecting sides of forged elements, such as ribs and webs [4]. They enhance the ability of these elements to withstand applied mechanical loads. Their design must satisfy both the requirements of metal flow in forging and the cost considerations arising from metal use and removal of metal by machining. The SKODA Auto forge shop practice is as follows:

Larger forging fillets (larger corner radius of the die) mean:

- The wear resistance of the die is greater, and the lifetime and forging precision increase.

- The relative share of the tooling cost in the total forging cost decreases.

- The metal flow in the die cavity is better.

- The machining of the forging deteriorates.

Lower die fillets (lower corner radius of forging) mean:

- The metal flow in the die cavity deteriorates.

- A corner of a forging may be unfilled, otherwise a higher load and/or a higher forging temperature is necessary. The thermal load of the die increases and the die life decreases.

- The maximum stress load in a given part of the die during forging increases.

- Changes in die design may be necessary, the use of die inserts increases the tooling cost.

\subsection{Parting line position}

The parting line is the projected line around the periphery of a forging that is defined by the adjacent and mating faces of the forging dies when the dies are closed. If the parting line remains straight around the periphery of the forging, it will lie in the forging plane. The forging plane corresponds to the plane of the mating die surfaces [4]. The forging plane is normal to the direction of closure of the dies. The shape and position of the parting line controls the metal flow, and influences the general type of process and equipment used. Once the parting line is located, the depth and position of the impressions in the upper and lower dies are fixed. The placement of the parting line ensures that the principal grain flow direction within the forging will be parallel to the direction of the principal loading. Thus the choice of proper placement should take into account:

- First - the manufacturing technique, i.e., forging methods, number of forging steps, etc.

- Second - metal flow optimisation according to the actual type of forging and forging sequence (preform stage or final stage, etc.).

\section{Customer's order for supply of precise forgings}

Let us suppose that a forge has received an order to produce near-net shape forgings. The first thing to be done is to evaluate the forge's own possibilities, which are substantially influenced by the forging design. This evaluation should be done within two basic domains:

\section{Production machines and equipment}

- Capacity of the forging machines in the forge shop. The nominal load is a function of the forging size.

- Ways of preforming, taking into account the shape difficulty factor of the forging.

- Number of preform steps in a particular forging machine that will be used for production.

- Production run (batch size), with reference to automation (need for robots, manipulators, transfer feeder, etc.).

- Method of die holder fastening.

- Presence of a stripping and ejection mechanism in a particular forging machine.

- Manner and method of billet preparation (quality of separating, obtainable weight tolerances, need for cross wedge rolling machine, roll forging machine, etc.).

- Ways of heating the billets (chamber furnaces, type of atmosphere used, induction heater, etc.).

- Ways of heat treatment (type, size and capacity of heating and annealing furnaces, etc.).

\section{Know-how}

- Possible use of numerical simulation (software and hardware used - 2D or 3D, CAD/CAM methods, etc.).

- Knowledge of basic and special forging methods (technological causalities, special preforming methods, die design, etc.).

- Customer's requirements regarding certification (VDA, ISO, etc.).

The decision whether to accept or turn down the contract is based on an evaluation of the above-mentioned items. This decision should take into account any further technical specifications and delivery conditions from the customer. After taking an affirmative decision, the economic aspects of the contract are elaborated. The share of individual costs in the forging price at the SKODA Auto forge (roughly estimated) is as follows:

\begin{tabular}{|l|l|l|l|}
\hline Material costs & $20-40 \%$ & Personnel costs & $20 \%$ \\
\hline Tooling costs & $30-40 \%$ & Overhead costs & $10 \%$ \\
\hline
\end{tabular}

Obviously, the materials and tools form a substantial part of the price. Hence it is necessary to consider very carefully if high forging precision, e.g., together with a low run size, is acceptable. The question is whether the cost saving due to limited machining is worth with increased tooling cost and the higher requirement for manufacturing production. The same consideration should be applied to different qualities of input material (type of bars). A low machining allowances value requires higher surface quality, and the price of the input material increases.

\section{Die design for near-net shape forging}

The basic problem in near-net shape forging is how to eliminate the influence of excess material. This excess material results from the permissible tolerances of billet volume 
variation, initial forging temperature variation, and the fact that we should include abrasive wear in the calculation (the internal die cavity volume gradually increases). This excess material in standard closed die forging process is accumulated in an external flash, which is trimmed. In flashless forging we need to look for some accommodating space in the die cavity. The region in which this space is situated will mostly depend on the shape of the component. We have three basic solutions:

1. Part of the forging remains underfilled within the approved dimensional tolerances.

2. The use of so called internal flash. If there is no central hole, some other part of the internal web, that will be punched can be used for this purpose.

3. Part of the forging can increase its dimensions. This may be the internal part in the case of an extruded hub, or the wall height of an extruded cup. It can be also the height of the gear rim or the flange height, etc.

\subsection{Forging into closed dies with accommodation in the corners of the forging}

This method of near-net shape forging seems to be very easily feasible. Cavity dies are completely closed and billet of constant volume is put inside. The shape of forging should have some region (usually peripheral edge radii), which may remain underfilled. This principle is used by HATEBUR forging machines. If we submit this process to analysis we recognise that the approach is rather ambitious. The cavity volume in relation to the admissible variation of the edge radii is very small. The dimensional accuracy of the billet should be very high (weight tolerance $0.5-1 \%$ ) and a narrow temperature range $\left(\approx \pm 30^{\circ} \mathrm{C}\right)$ is necessary.

The foregoing conditions are rather difficult to execute if using a standard forging press. To ensure the stability of the process it is to a very limited extent possible exploit the elastic deformation (stiffness) of both the machine and the tool. When the die cavity is completely filled, some excess billet volume can be accommodated in machine distortion. The example of such a forging with unfilled corners is in the Fig. 2.

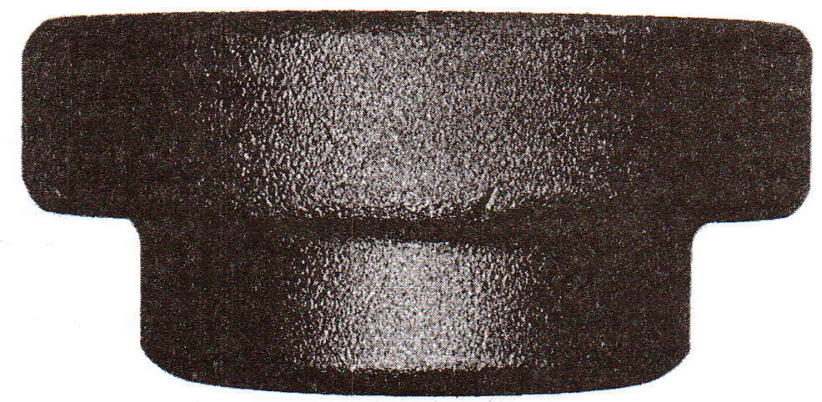

Fig. 2: Accommodation space in unfilled corners

This method has advantages in the simplicity of the die design and the low number of forging operations, but on the other hand precise billet volume is necessary and there is a risk of press overloading. To avoid this danger we must keep a narrow range of technological process conditions, e.g., temperature, press adjustment, lubrication, etc.

\subsection{Forging into closed dies with accommodation into internal flash}

This method is also called flashless forging. It is usually used when forging axisymmetrical parts with a central hole. The excess material is accommodated in the central part of the forging in the form of an "internal flash", and is removed by punching. This is done when producting rings, wheels and gears. The die design for individual preform steps should be done in such a manner that the metal flow in the finished die cavity is in the central web only. Other die cavity parts have to be properly filled without forming a fin of material between the punch and the container in the die closure position.

Die design rules for preform operations.

1) The goal of preforming operations is to distribute the material in such a manner that the material flow in the finished forging operation will be optimal. This means ensuring a minimal path of deformation and a minimal degree of deformation. Short flow distances and low values of contact pressure diminish abrasive wear of the die.

2) The basic goal of preform operation is to create a "space" in the forging axis region that will be used for accommodating of excess material in the next forging step, see Fig. 3. The dimensions and shape of this cavity are projected according to type of forging and the shape of the die, with goal of making the flow of material as simple as possible.

3) In the case of preforming there is no accommodation space in the die cavity. Thus the volume of the cavity in a preform die should be a little larger than the maximum possible billet volume. The designer proposes the shape of the cavity and its dimensions in such a way that some space remains unfilled even if the billet volume and forging temperature are at their upper limits. This space should be positioned at the place that is the last to be filled. Generally, this is the region of die closure. This is a safety precaution against press overloading and prevents creating a fin.

Die design rules for finish operation.

The shape and dimensions of this final cavity correspond to the forging shape, with the exception of creating an accommodation space in the central region of the forging axis. This space must be designed in such a manner as

- to be able to accommodate the maximum possible billet excess volume, and

- to ensure perfect filling of the die cavity for the whole range of billet volume and technological conditions.

This method has the advantages that more complicated shapes can be forged and the volume accuracy of a billet may be lower because the accommodation space is greater. On the other hand, this means higher material consumption. The excess material in an internal flash has to create sufficient pressure for filling. The forging process itself requires more forging operations. The outcome is that it is necessary to ensure precise positioning of the preform, we need a larger 


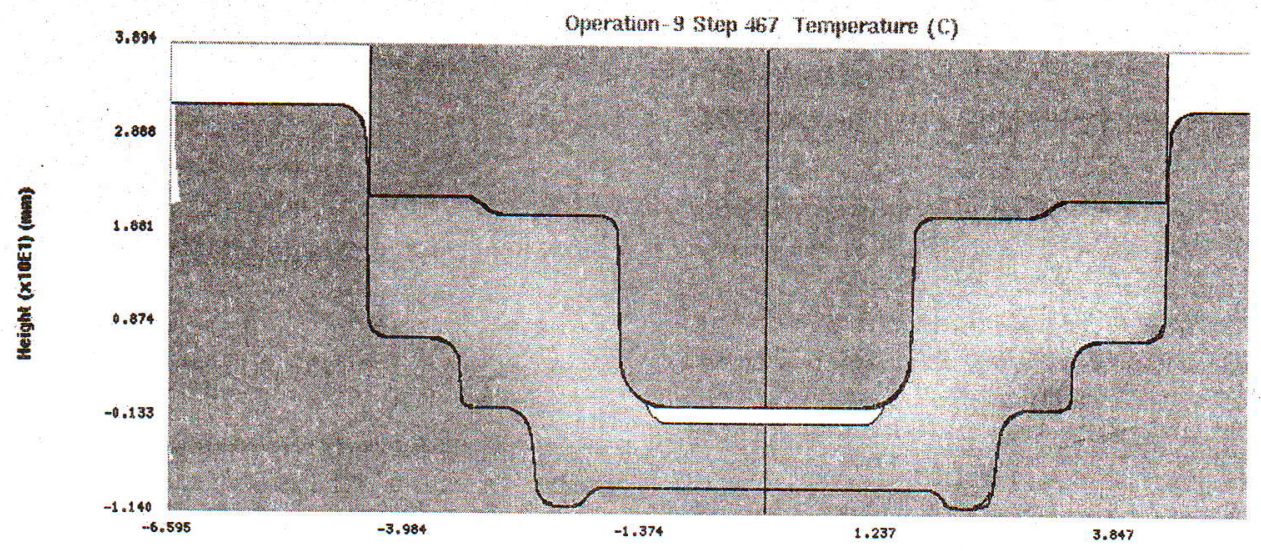

Fig. 3: Accommodation space in the central internal web

working (clamping) area in the forging machine, and the shift output is lower.

\subsection{Forging into closed dies with accommodation into forging height}

The principle of this technique is given by the fact that the excess material is "transferred" into the forging height - either the total forging height or the height of a part of the forging - according to the current preform volume. This is achieved by special die design when the upper die or a part of die is sprung. Special multi-part dies with springing should be used [2]. In the SKODA Auto forge, a special die holder has been developed, which can change the dies and spring-operated elements quickly [5]. An important condition when using this technique is that these spring elements should have a given pressure value preset, so that the relative movement can occur only under given conditions.

The metal flow in a sprung die can be divided into two steps:

- First step: The die cavity gradually fills. Towards the end, when the metal reaches the peripheral corners, the load starts increasing

- Second step: When the die cavity is completely full the significant increase in forging load produces a relative movement of the main surface 'of the die and the excess material can be accommodated in the space that arises.

The limitations of using this technique as follows:

1) Maximum billet excess volume: The height of forging has a certain tolerance. The maximum volume to be accommodated is the product of this value and the billet cross-section. This volume is compared with the billet volume tolerance given by the type of bar, its dimensions and the method of separation. According to practical experience in the SKODA Auto forge, the weight tolerance of billets used for close die forging of gears is $\pm 10 \mathrm{~g}$. This is the case for forging with outer diameter $70 \mathrm{~mm}$ and height tolerance $\pm 0.4 \mathrm{~mm}$. This value corresponds with the range of $1-2 \%$ according to the forging weight. This precision of separation can be achieved by using standard shears.

2) Forging dimensions: A rough estimation of the forging load is based on the forging cross-section and the forging pressure. In this case the forging load should be increased for about a value of load generated by the load-limiting device. At this force, the device should act against the movement of the die, even if there is no material. The design of such a device (jig) for eliminating this load of about 0.8 to $1.8 \mathrm{MN}$ ( e.g., for case of transmission wheels) is rather spatially demanding. To decrease this load, a multi-part device can be used and the pressure acting on the "floating" part of die only can be eliminated.

3) General rule for die design: In this case it is not necessary to use a preform forging stage, because the excess material is accommodated in the finished operation. The first forming step is upsetting between the flat dies in the same manner as for other methods. The shape of the final die cavity corresponds to the forging shape. If it is necessary to eliminate just a part of the load, split dies should be used.

This forging method is generally comparable with forging where the accommodation space is in the corners of the forging. The principle difference is that the accuracy of billet dimensions can be lower because the accommodation space may be greater. Adjusting the machine stroke is also easier here. The forging height is a function of the billet volume,

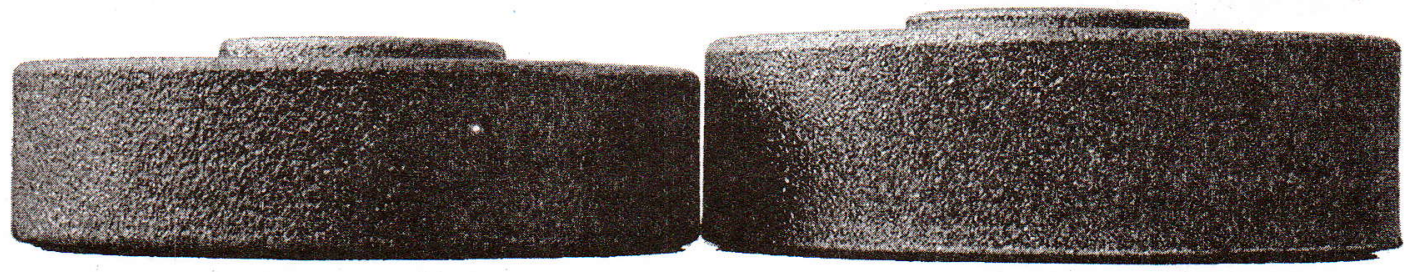

Fig. 4: Accommodation space in different forging height 
Table 2

\begin{tabular}{|l|l|l|}
\hline Method of accommodation & Advantages & Disadvantages \\
\hline Space in edge radii & $\begin{array}{l}\text { Simple die design. } \\
\text { Low number of forging operations. }\end{array}$ & $\begin{array}{l}\text { Precise billet volume. } \\
\text { Narrow range of process conditions. } \\
\text { Risk of press overloading. }\end{array}$ \\
\hline Space in internal flash & $\begin{array}{l}\text { Lower billet volume accuracy. } \\
\text { Complicated shapes can be forged. }\end{array}$ & $\begin{array}{l}\text { Low shift output, more operations. } \\
\text { Precise positioning of preform. } \\
\text { Higher material consumption. }\end{array}$ \\
\hline Space in forging height & $\begin{array}{l}\text { Lower billet volume accuracy. } \\
\text { High shift output. } \\
\text { Easy machine adjustment. }\end{array}$ & $\begin{array}{l}\text { More sophisticated and more expen- } \\
\text { sive tool design. } \\
\text { Special spring-operated device. }\end{array}$ \\
\hline
\end{tabular}

but without the influence of press stiffness. The main disadvantage is that more sophisticated tool design is necessary. A special spring-operated device is needed.

\section{Conclusion}

The production of near-net shape forgings, using conventional forging equipment, is practically possible. Elimination of the conventional flash involves solving of a basic problem, which is how to accommodate the excess billet material. This study has concentrated on forgings of rotational shape. Three different methods of die design were developed. A résumé of advantages and disadvantages is given in Table 2. The decision on which method use, depends on the forging dimensions, forging shape complexity, run size, and the stability of the process conditions. Future research will focus on forgings of oblong shapes. The fundamental condition for successful solution is the use of advanced numerical simulation software.

\section{Acknowledgments}

This research has been conducted in the framework of CTU in Prague research project No. J04/98:212200008 and in collaboration with the SKODA Auto forge shop.

\section{References}

[1] Schmiedeteile: Gestaltung, Anwendung, Beispiele. Web site: http://www. ids.wsm-net.de

[2] Dean, T. A.: Die Technology. The Feasibility of Flashless Forging. In: "Metallurgia and Metal Forming". Redhill
(England): Fuel \& Metallurgical Journals Ltd., November 1977, p. 488-498.

[3] Čermák, J., Vrabec, M., Horák, J.: Computer Aided Optimisation of Die Design and Production. In: International Conference on Advanced Engineering Design. Glasgow, University of Glasgow, 2001, p. 300-304.

[4] Forging Design Handbook. American Society for Metals. Metals Park, Ohio. 1972.

[5] Gráf, G., Čermák, J.: Close-Die Flashless Forging in Automotive Industry. In: Journal for Technology of Plasticity. Novi Sad (Yugoslavia): Fac. of Technical Sciences. Inst. for Prod. Eng., Vol. 26, No. 2, 2001, p. 1-10.

Dr. Jan Čermák

e-mail: jan.cermak@fs.cvut.cz

Department of Manufacturing Engineering

Czech Technical University in Prague

Faculty of Mechanical Engineering

Technická 4

16607 Prague 6, Czech Republic

Ing. Gustav Gráf

e-mail: gustav.graf@skoda-auto.cz

Department of Forge Technology

SKODA Auto, a.s.

V. Klimenta 869

29360 Mladá Boleslav, Czech Republic 